\title{
LAS CONSECUENCIAS JURÍDICAS DE LOS DEFECTOS MORALES DEL DERECHO: UNA PROPUESTA A PARTIR DEL DEBATE ENTRE ALEXY Y FINNIS
}

\author{
José Chávez-Fernández Postigo \\ Doctor en Derecho por la Universidad de Zaragoza \\ Profesor de Filosofía del Derecho \\ Universidad Católica San Pablo, Arequipa \\ Contacto: jchavezfernandez@ucsp.edu.pe
}

Recibido: 10 de junio de 2021

Aprobado: 23 de agosto de 2021

Para citar este artículo:

Chávez-Fernández Postigo, J. (2021). "Las consecuencias jurídicas de los defectos morales del Derecho: una propuesta a partir del debate entre Alexy y Finnis”. Prudentia Iuris, N. 92, pp. 125-158 DOI: https://doi.org/10.46553/prudentia.92.2021.pp.125-158

Resumen: Se elabora una propuesta básica de comprensión de las consecuencias jurídicas de los defectos morales del Derecho a partir de la valoración del debate entre Alexy y Finnis en The American Journal of Jurisprudence (2013 y 2014), y en The Cambridge Companion to Natural Law Jurisprudence (2017). El trabajo se divide en dos partes. En la primera se sintetiza, por un lado, la principal coincidencia entre ambos enfoques y, por otro lado, sus discrepancias básicas. En la segunda parte se elabora una propuesta alternativa. Para ello, primero, se justifica la pertinencia de un diálogo entre sus argumentos. Segundo, se defiende que una comprensión apropiada de la versión alexiana de la fórmula de Radbruch puede dar cuenta adecuadamente de las consecuencias jurídicas prácticas de los defectos morales del Derecho, pero solo si se le formula 


\section{JOSÉ CHÁVEZ-FERNÁNDEZ POSTIGO}

desde una órbita semántica análoga a la de los planteamientos básicos de Finnis. Tercero, se ofrece la opinión del autor sobre el tópico.

Palabras clave: Alexy, Finnis, Debate, Relación Derecho y moral, Injusticia extrema, Fórmula de Radbruch. 


\title{
The juridical consequences of the law's moral defects: a proposal based on the debate between Alexy and Finnis
}

\begin{abstract}
A basic proposal for the understanding of the juridical consequences of the law's moral defects is elaborated on the basis of the debate between Alexy and Finnis in The American Journal of Jurisprudence (2013-2014), and The Cambridge Companion to Natural Law Jurisprudence (2017). The article is divided in two parts. In the first one, a synthesis is made between, on the one hand, the main coincidence between both approaches, and on the other, their basic discrepancies. In the second, an alternative proposal is elaborated. Thus, first, the pertinence of a dialogue between their arguments is justified. Second, it is defended that a proper understanding of the Alexian version of the Radbruch's formula can adequately account for the juridical consequences of the law's moral defects, but only if it is formulated from a semantic orbit which is analogue to the basic claims of Finnis. Thirdly, the author's opinion on the subject is given.
\end{abstract}

Keywords: Alexy, Finnis, Debate, Relationship between law and morality, Extreme injustice, Radbruch's formula.

\section{Le conseguenze giuridiche dei defetti morali del diritto: una proposta basata sul dibattito tra Alexy e Finnis}

Sommario: L'articolo fa una proposta per comprendere le conseguenze giuridiche dei defetti morali nel diritto basata sul dibattito tra Alexy e Finnis in The American Journal of Jurisprudence (2013 e 2014) e in The Cambridge Companion to Natural Law Jurisprudence (2017). Il lavoro è diviso in due parti. La prima parte sintetizza, da un lato, la principale coincidenza tra i due approcci e, dall'altra, le loro discrepanze fondamentali. Nella seconda parte viene elaborata una proposta alternativa. Per fare ciò, in primo luogo, è giustificata la pertinenza di un dialogo tra i loro argomenti. In secondo luogo, si sostiene che una corretta comprensione della versione alessiana della formula di Radbruch può adeguatamente spiegare le conseguenze giuridiche pratiche dei difetti 
JOSÉ CHÁVEZ-FERNÁNDEZ POSTIGO

morali del diritto, ma solo se è formulata da un'orbita semantica analoga all'approccio di Finnis. In terzo luogo, viene offerta l'opinione dell'autore su questo tema.

Parole chiave: Alexy, Finnis, Dibatitto, Rapporto fra diritto e morale, Estrema ingiustizia, Formula di Radbruch.

\section{Introducción}

En este trabajo ${ }^{1}$ me propongo elaborar una propuesta básica de comprensión de algunas de las consecuencias jurídicas principalmente prácticas, pero también teóricas, de los defectos morales del Derecho, lo que ensayaré a partir de la valoración crítica del célebre debate entre Alexy $^{2}$ y Finnis ${ }^{3}$, y que continúa de alguna manera con la réplica de $\mathrm{Alexy}^{4}$.

En ese sentido, dividiré el trabajo en dos partes. En la primera (II), me ocuparé de organizar sintética y sistemáticamente lo que entiendo que son, por un lado, la principal coincidencia entre ambos enfoques (II.1.) y, por otro lado, tanto las discrepancias básicas de los autores referidas a las consecuencias jurídicas teóricas de los defectos morales del Derecho (II.2.), como a las consecuencias jurídicas prácticas de los mismos (II.3.). En la segunda parte (III), trataré de elaborar a muy a grandes rasgos una propuesta básica de comprensión alternativa. Para ello, en primer lugar, justificaré la posibilidad y la utilidad de un diálogo entre los argumentos de Alexy y de Finnis, no obstante situarse -como es sabido- en tradiciones de pensamiento muy diferentes (III.1.). En segundo lugar, intentaré defender con algo de detalle que una comprensión razonable y flexible de la versión alexiana de la fórmula de Radbruch puede dar cuenta adecuadamente de las consecuencias jurídicas prácticas de los defectos morales del Derecho, pero -paradójicamente- solo si se le formula desde una órbita semántica análoga a la de los bienes humanos básicos y las exigencias de la razona-

1 Este artículo ha sido financiado como ganador del Concurso de Proyectos de Investigación y Fondos Semilla 2018 de la Universidad Católica San Pablo, Arequipa, Perú. Proyecto UCSP-2018-PI-01. Quiero agradecer los valiosos comentarios críticos y sugerencias de Luciano Damián Laise y Piero Ríos Carrillo sobre un primer borrador del texto.

2 Alexy, R. (2013). "Some Reflections on the Ideal Dimension of Law and on the Legal Philosophy of John Finnis". The American Journal of Jurisprudence, Nro. 58, 97-110.

3 Finnis, J. (2014). "Law as Fact and as Reason for Action: A Response to Robert Alexy on Law's 'Ideal Dimension”. The American Journal of Jurisprudence, Nro. 59, 85-109.

4 Alexy, R. (2017a). "The Ideal Dimension of Law". En G. Duke y R. P. George (eds.). The Cambridge Companion to Natural Law Jurisprudence. Cambridge. Cambridge University Press, 314-341. 
bilidad práctica que postula Finnis (III.2.). En tercer lugar, ofreceré muy brevemente mi opinión sobre la relevancia de las consecuencias jurídicas teóricas de los defectos morales del Derecho (III.3.). En cuarto y último lugar, culminaré el trabajo con un breve colofón como reflexión final (IV).

\section{Una síntesis de los puntos centrales del debate Alexy-Finnis}

En esta primera parte más descriptiva me he inclinado por componer un cuadro muy sintético que pretende sistematizar las coincidencias y controversias más importantes de las tesis defendidas por ambos autores, por lo que no incidiré en todos los detalles del debate ${ }^{5}$. Opté por la estructura diseñada porque creo que puede facilitar la elaboración de la propuesta que ensayaré en la última parte (III) de este trabajo.

\section{II.1. Una coincidencia sustancial: los defectos morales del Derecho tienen consecuencias jurídicas}

Parto de una idea nuclear admitida tanto por Alexy como por Finnis en el debate, aunque desde distintos enfoques y tradiciones. Me refiero a la tesis de que los defectos morales del Derecho tienen consecuencias cualitativas sobre él, es decir, que afectan su calidad en cuanto Derecho o -en un sentido relevante, como veremos- su validez jurídica.

Para Alexy 6 , en concreto, la tesis de la vinculación conceptual entre el Derecho y la moral resulta operativa respecto de la distinción entre nopositivismo y positivismo jurídico si es que se le entiende desde la tesis de la necesidad que él defiende, esto es, en el sentido de que existe una conexión necesaria entre, por un lado, la validez o corrección jurídica y, por otro lado, los méritos morales o la corrección moral del Derecho. Dicho de otro modo:

5 Para detalles complementarios, puede verse: Nava Tovar, A. (2017). "Non-Positivism, the Radbruch Formula, and the Dual Nature of Law. Some Remarks on the Finnis-Alexy Debate". En M. Borowski, S. L. Paulson y J. R. Sieckmann (eds.). Rechtsphilosophie und Grundreschtstheorie. Robert Alexys System. Tübingen. Mohr Siebeck, 161-174; o también: De Rosa, E. (2017). "Validez legal y corrección moral. El problema de la ley injusta en la teoría jurídica de John Finnis”. Prudentia Iuris, Nro. 87, 277-298. Vale la pena señalar que para cuando ambos trabajos fueron escritos, aún no se había publicado la última pieza del debate: Alexy, R. "The Ideal Dimension...”. Ob. cit.

6 Alexy, R. (2013). “Some Reflections...”. Ob. cit., 98-99. 
JOSÉ CHÁVEZ-FERNÁNDEZ POSTIGO

para Alexy ${ }^{7}$, las deficiencias o incorrecciones morales -o de justicia- del Derecho no se restringen al ámbito de la moral -tesis que sería ciertamente trivial-, sino que tienen también, al menos, efectos "cualificantes" sobre el mismo, es decir, sobre su validez en cuanto Derecho.

Basta señalar por ahora que $\mathrm{Alexy}^{8}$, no obstante echar en falta que Finnis no aplique a su propia teoría conceptos normativos para justificar dicha conexión necesaria cualificante entre el Derecho y la moral -o la justicia-, acepta que las distinciones y los estándares finnisianos lo ponen bastante cerca a la tesis de la conexión cualificante que él mismo propone.

Para Finnis $^{9}$ (2014, p. 90), por su parte, es precisamente el análisis alexiano que busca necesidades conceptuales el que los distancia en este punto $^{10}$. Como veremos más adelante (III.2.), el enfoque de Finnis tiene que ver antes bien con cómo los bienes o valores humanos básicos y los medios disponibles se combinan para comprender y operar adecuadamente el Derecho. En ese orden de ideas, para Finnis ${ }^{11}$, los defectos morales del Derecho tienen efectos sobre el sentido en que lo entendemos, dado que el Derecho injusto no sería "Derecho" en el sentido focal o central del término, sino que su injusticia terminaría relegándolo -por decirlo de alguna manera- a un sentido secundario, periférico o restringido del término, aunque auténtico, analógicamente hablando.

\section{II.2. Una discusión sobre las consecuencias jurídicas teóricas de los defectos morales del Derecho}

Me ocuparé ahora de lo que llamo "consecuencias teóricas" de la tesis inicial, en concreto, de dos debates que están estrechamente conectados. El primero versa sobre la "doble naturaleza" (Alexy) o la "doble vida" (Finnis) del Derecho; el segundo, acerca de la discusión taxonómica respecto de las concepciones iusfilosóficas, en concreto, sobre la pertinencia del rótulo "nopositivismo" y sus especificaciones.

7 Alexy, R. (2004). El concepto y la validez del Derecho (trad. J. M. Seña). $2^{\text {a }}$ edición. Gedisa, 32. Confrontar, también: Alexy R. "The Ideal Dimension...”. Ob. cit., 326 y ss.

8 Alexy, R. “Some Reflections...”. Ob. cit., 105-107.

9 Finnis, J. "Law as Fact...”. Ob. cit., 90.

10 En su réplica a Finnis, el profesor alemán insiste en su enfoque: Alexy, R. "The Ideal Dimension...”. Ob. cit., 317 y ss.

11 Finnis, J. (2000). Ley natural y Derechos Naturales (trad. C. Orrego). Buenos Aires. Abeledo-Perrot, 391. 


\section{II.2.1. Sobre las dimensiones o las vidas del Derecho}

Alexy ${ }^{12}$ concibe al Derecho como "la institucionalización de la razón", es decir, como teniendo una "doble naturaleza" o una "dimensión dual". Por un lado, tendría una dimensión real o fáctica, por la que serían parte del Derecho tanto los actos de la autoridad legítima, como la eficacia social de dichas decisiones. Por otro lado, tendría también, necesariamente, una dimensión ideal o crítica, por la que el Derecho debería ser, además, razonable, o dicho de otro modo, moralmente correcto ${ }^{13}$.

Esta tesis se sostendría en tres pasos ${ }^{14}$. El primero, el argumento de la pretensión de corrección, por el cual tanto las normas y las decisiones jurídicas individuales como los sistemas jurídicos tomados en su conjunto formularían necesariamente una pretensión de corrección, al menos, implí$\operatorname{cita}^{15}$. El segundo, el argumento sobre la posibilidad de la corrección moral y del contenido de la dimensión ideal del Derecho, el que se construiría con la justificación discursiva de los Derechos Morales como elementos fundamentales de justicia, a partir de las reglas del discurso práctico general. El tercero, marcado por el impacto de la dimensión crítica en la dimensión institucional, una ponderación entre los principios de justicia y de seguridad jurídica que sería dependiente de lo que veremos en el siguiente acápite (II.3.) con el rótulo de "consecuencias jurídicas prácticas" de los defectos morales del Derecho.

A Finnis ${ }^{16}$, por su parte, las ideas de naturaleza dual o doble dimensión le parecen esquivas, aunque admite que se esclarecen hasta cierto punto a la luz de la discusión sobre las dos perspectivas o puntos de vista: la del observador y la del participante, de las que me ocuparé más adelante (II.3.1.) ${ }^{17}$. En todo caso, al profesor australiano le parece un error abordar el problema a través de dimensiones "reales" e "ideales", y en particular,

12 Alexy R. "Some Reflections...". Ob. cit., 99-100.

13 Con más detalle: Alexy, R. (2011). "La doble naturaleza del Derecho" (trad. Jorge Portocarrero). En C. Bernal Pulido (ed.). La doble dimensión del Derecho. Autoridad y razón en la obra de Robert Alexy. Lima. Palestra, 29 y ss. Sobre esta tesis se puede revisar: Sodero, E. (2017). "Concepto de derecho, moral y dignidad". En R. Alexy et al. (ed.). Argumentación, Derechos Humanos y justicia. Buenos Aires. Astrea, 55 y ss.

14 Alexy R. "Some Reflections...". Ob. cit., 100 y ss.

15 Para más detalles sobre este punto, confrontar: Alexy, R. (2005). "La crítica de Bulygin al argumento de la corrección" (trad. P. Gaido). En R. Alexy y E. Bulygin. La pretensión de corrección del Derecho. La polémica sobre la relación entre Derecho y moral. $5^{\mathrm{a}}$ reimp. Bogotá. Universidad Externado de Colombia, 53 y ss.

16 Finnis, J. "Law as Fact...". Ob. cit., 86.

17 Para Alexy, en cambio, estas dimensiones serían solidarias de dichas perspectivas, por lo que no se podría aceptar las segundas, como hace Finnis, rechazando las primeras. Revisar: Alexy, R. "The Ideal Dimension...". Ob. cit., 325-326. 
JOSÉ CHÁVEZ-FERNÁNDEZ POSTIGO

asimilarlas a principios que se conciben en tensión potencial, como el de seguridad jurídica y el de justicia, puesto que esto solo sería posible si los principios operasen en el mismo plano, que en el contexto alexiano tendría que ser el ideal, lo que provocaría una confusión entre el ser y el deber ser $^{18}$. Para Finnis ${ }^{19}$, sería precisamente a causa del principio de justicia, que deberíamos tener leyes positivas identificables con seguridad a través de fuentes sociales fácticas de validez, en la medida de lo posible.

Finnis $^{20}$, si de metáforas se trata, prefiere una distinta a la de Alexy: a su juicio, la ley tendría una "doble vida": a) como razón para la acción, y b) como hecho, en el sentido de haber sido promulgada por el legislador y luego aceptada por funcionarios y ciudadanos como tal. En su opinión ${ }^{21}$, el suyo se trataría de un enfoque más conveniente, pues evidenciaría mejor, por un lado, hasta qué punto el Derecho puede ser estudiado con provecho tanto desde la perspectiva de un participante (a), como desde la perspectiva de un observador (b); y por otro lado, mostraría la complejidad en las relaciones entre ambos puntos de vista, dado que el razonamiento jurídico implica tanto premisas normativas como fácticas. Dicho brevemente: la metáfora finnisiana de la doble vida explicaría mejor que la alexiana de la naturaleza dual, la importancia relativa y la interrelación de las perspectivas metodológicas del participante y del observador ${ }^{22}$.

\section{II.2.2. Sobre la viabilidad de la categoría "no-positivismo jurídico"}

Una vez que $\mathrm{Alexy}^{23}$ se sitúa ya no solo en la tesis de que las deficiencias morales del Derecho tienen consecuencias cualificantes sobre él, sino que las puede tener también "clasificantes", distingue entre a) "no-positivismo súper-incluyente": cuando se afirma que ningún defecto moral del

18 Alexy, por su parte, destaca que no hace aquello de lo que se le acusa: el principio de seguridad jurídica -de carácter normativo- no se identificaría con la dimensión real del Derecho -de carácter más bien fáctico. Confrontar: Alexy, R. “The Ideal Dimension...”. Ob. cit., 331-332.

19 Finnis, J. “Law as Fact...”. Ob. cit., 101.

20 Finnis, J. "Law as Fact...". Ob. cit., 95.

21 Con más detalle: Finnis, J. (2011). "Adjudication and Legal Change”. En Philosophy of Law. Collected Essays (vol. IV). Oxford. Oxford University Press, 397 y ss.

22 Me parece que Alexy responde mostrando la complejidad de su propuesta: la fórmula de Radbruch sería tan solo el primer paso de cinco por los que sería posible determinar la relación entre la dimensión real e ideal del Derecho a partir de la idea central de la corrección. Revisar: Alexy, R. “The Ideal Dimension...". 329-330.

23 Alexy, R. “Some Reflections...”. Ob. cit., 105-108. 
Derecho afecta su validez jurídica; b) "no-positivismo excluyente": cuando se sostiene que cualquier defecto moral del Derecho lo hace; y c) "no-positivismo incluyente": cuando se mantiene que solo la injusticia extrema afecta la validez jurídica. Para Alexy, solo esta última forma expresaría la ponderación adecuada entre la dimensión real y la ideal del Derecho, y entre la seguridad jurídica y la justicia, siendo el tipo de no-positivismo con el que se identifica. A su juicio, por el contrario, Finnis, en la primera edición de $\mathrm{Na}$ tural Law and Natural Rights (NLNR), sería claramente un no-positivista súper-incluyente, dado que su tesis del caso central y del periférico del término Derecho, no llegaría a expresar a cabalidad esa ponderación necesaria, aunque se abre a la posibilidad de que el profesor australiano se haya acercado más al enfoque que Alexy defiende en trabajos posteriores.

Por su parte, Finnis ${ }^{24}$ argumenta contra el término "no-positivista" para catalogar una filosofía jurídica, básicamente porque conferiría a los que se autodenominan positivistas una posición u opción "por defecto" que no se sostiene ni histórica ni teóricamente. No obstante, con el objeto de responder a las alusiones de Alexy, accede a sostener que desde NLNR mantiene -en algún sentido, claro está- las tres posiciones no-positivistas señaladas por el profesor alemán respecto de las consecuencias de la ley injusta, pero en su justo lugar. En ese sentido, Finnis ${ }^{25}$, a su propio juicio: a) desde la perspectiva del observador -la que haría parte de la perspectiva del participante moralmente comprometido- sería, secundariamente, un no-positivista súper-incluyente; b) desde la perspectiva del participante sería, principalmente, un no-positivista excluyente; y c) desde la perspectiva de participantes particulares y contextualizados, podría ser algo cercano a un no-positivista incluyente.

Con lo señalado me parece que queda claro que lo que he llamado aquí consecuencias jurídicas teóricas de los defectos morales del Derecho, termina por resolverse con el esclarecimiento de las consecuencias jurídicas prácticas del mismo, debate del que me ocuparé de inmediato.

\section{II.3. Una discusión sobre las consecuencias jurídicas prácticas de los defectos morales del Derecho}

Los dos temas que abordaré ahora completan la exposición de los que me parecen los puntos centrales del debate. El primero, sobre la naturaleza de las perspectivas del participante y del observador (Alexy) -o de los puntos

24 Finnis, R. "Law as Fact...”. Ob. cit., 96-98.

25 Ibídem, 86 y 108-109. 
JOSÉ CHÁVEZ-FERNÁNDEZ POSTIGO

de vista interno y externo (Finnis), que para los efectos de esta discusión entenderé como equivalentes ${ }^{26}$ - y su relevancia práctica para el conocimiento del Derecho. El segundo -y central-, el debate acerca de la pertinencia de la versión alexiana de la fórmula de Radbruch en orden a su operatividad ${ }^{27}$.

\section{II.3.1. Sobre las perspectivas o los puntos de vista jurídicos}

Para Alexy ${ }^{28}$, la diferencia entre la perspectiva del observador y la del participante es básicamente la siguiente. La primera estaría confinada a los hechos sociales e interesada solo en la dimensión real del Derecho, lo que no permitiría sino justificar qué es lo que realmente -se entiende: fáctica o empíricamente-se decide en un determinado sistema jurídico. Por el contrario, la segunda permitiría, además, justificar cuál es la respuesta jurídicamente correcta en dicho sistema sobre la base de argumentos normativos no necesariamente basados en hechos -es decir: razones morales, concretamente, de justicia ${ }^{29}$, por lo que la mirada propia del juez ocuparía el centro de esta perspectiva $^{30}$. En ese sentido, la perspectiva del participante sería la principal, ya que sin ella serían imposibles los sistemas jurídicos ${ }^{31}$. Pero resta hacer una precisión importante: para Alexy, la perspectiva del observador permitiría consideraciones "indirectas" - a diferencia de las directas propias de la perspectiva del participante- respecto de lo que éste observa que los participantes consideran Derecho moralmente correcto. Si bien el enfoque descrito lo había llevado a afirmar que desde la perspectiva del observador el iuspositivismo sería correcto ${ }^{32}$, ahora Alexy ${ }^{33}$ introduce una excepción: no lo sería si lo que se observa es un sistema que en su conjunto no formula

26 En ese sentido: Finnis, J. "Law as Fact...”. Ob. cit., 94.

27 Cuestión que no agota la propuesta de Alexy, pero que juzga una suerte de "piedra de toque" de la discusión sobre el positivismo o no-positivismo. Revisar: Alexy, R. "The Ideal Dimension...”. Ob. cit., 321.

28 Alexy, R. "Some Reflections...". Ob. cit., 103-104.

29 Con más detalle: Alexy, R. (2016). "La justicia como corrección" (trad. J. A. Seoane y E. Sodero). En La institucionalización de la justicia. $3^{a}$ edición ampliada. Granada. Comares, $47 \mathrm{y} \mathrm{ss.}$

30 Alexy, R. El concepto y la validez... Ob. cit., 31. Revisar también: Alexy, R. “The Ideal Dimension..... Ob. cit., 326.

31 Alexy, F. "Some Reflections...". Ob. cit., 104.

32 Alexy señala: "Yo no manifiesto que la tesis de la separación esté equivocada desde ambos puntos de vista. Lo está solamente desde la perspectiva del participante. Por el contrario, desde la perspectiva del observador dicha tesis es correcta". [Alexy, R. (2013). "Una respuesta a Joseph Raz". En G. Pavlakos (ed.). Derecho, derechos y discurso. La Filosofía jurídica de Robert Alexy (trad. Jorge Portocarrero). Bogotá. Universidad Externado de Colombia, 73].

33 Alexy, R. "Some Reflections...". Ob. cit., 109. 
en absoluto una pretensión de corrección, en cuyo caso, el observador vería ciertamente cómo son tomadas de hecho las decisiones, pero no cómo son tomadas en cuanto Derecho, ya que no se estaría observando un sistema jurídico ${ }^{34}$.

Finnis $^{35}$, por su parte, coincide con Alexy en que la perspectiva primaria para aproximarse a la operatividad del Derecho es la del participante, pero es crítico con el modo alexiano de entender la perspectiva que considera secundaria y derivada: la del observador. Entiende que, para Alexy, la dimensión real del Derecho se identificaría con todo lo relacionado al Derecho susceptible de captarse desde esta perspectiva secundaria. Destaca críticamente que el observador alexiano no fuese concebido ni como un realista sociológico ni como un historiador del Derecho, sino como alguien capaz de entender e incluso aplicar con precisión todos los criterios de validez y decisión vinculados a la autoridad y a la eficacia en un determinado sistema jurídico ${ }^{36}$.

Para Finnis ${ }^{37}$, una caracterización tan amplia de la perspectiva del observador tendría, al menos, un par de consecuencias: a) Alexy estaría aceptando implícitamente que hay una perspectiva teórica sólida desde la que es correcto -y no súper-incluyente, si se le toma como calificativo peyorativo de exceso- referirse con términos como Derecho o validez jurídica a leyes monstruosamente injustas, como lo hace el propio Finnis ${ }^{38}$; y b) Alexy no

34 Para Alexy: "Lo que vale para una norma aislada no tiene por qué valer para el sistema jurídico como un todo", por lo que "desde la perspectiva del observador, la tesis positivista de la separación es esencialmente correcta. Tan solo en el caso extremo y fácticamente improbable de un sistema normativo que ni siquiera formule una pretensión de corrección, tropieza con un límite”. (Alexy, R. El concepto y la validez... Ob. cit., 37 y 41, respectivamente).

35 Finnis, J. "Law as Fact...”. Ob. cit., 87-89.

36 Por lo que ve contradictoria con esto, la afirmación alexiana: "El observador, qua observador, tan solo puede describir la práctica del Tribunal Constitucional y el debate en el cual el Tribunal se encuentra inmerso. Él no puede comprometerse en la argumentación en torno a cuál de las respuestas es jurídicamente correcta. Tan pronto haga eso, dejará de ser un observador y pasará a ser un participante”. (Alexy, R. “Una respuesta a...”. Ob. cit., 73-74).

37 Finnis, J. "Law as Fact...”. Ob. cit., 89-90.

38 En concreto: "Lejos de 'negar validez jurídica a las reglas inicuas' [referencia a Hart], la tradición otorga explícitamente (al hablar de 'leyes injustas') [referencia a Tomás de Aquino] validez jurídica a las reglas inicuas, ya con el fundamento de y en el sentido de que estas reglas son acepadas en los tribunales como orientaciones para la decisión judicial, ya con el fundamento de y en el sentido de que, a juicio del hablante, ellas satisfacen los criterios de validez establecidos por las reglas jurídicas constitucionales o de otro tipo" (Finnis, J. Ley natural y derechos... Ob. cit., 392). Y dicha postura, lejos de ser matizada como sugiere Alexy, es más bien

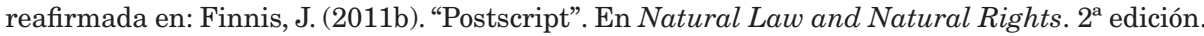
Oxford. Oxford University Press, 476. 
desafiaría explícitamente la tesis de $\mathrm{Hart}^{39}$ - como sí lo haría Finnis ${ }^{40}$ - respecto de que un punto de vista interno no comprometido necesariamente con la moralidad del Derecho fuese capaz de entenderlo a cabalidad y de operar con él, situación que dejaría a los iuspositivistas en una cómoda posición: sin la necesidad de recurrir ni teórica ni prácticamente a la alexiana dimensión ideal del Derecho ${ }^{41}$.

En todo caso, para Finnis ${ }^{42}$, desde un punto de vista interno comprometido razonable o moralmente con el Derecho, éste sería concebido como un conjunto sólido de razones para la acción ${ }^{43}$; pero desde el punto de vista externo, podría ser también observado al modo en que lo hacen los iuspositivistas, "como un puro hecho social de poder" 4 , aunque esta observación por sí sola tendría escasa importancia teórica dado que no se podría captar la razón principal por la que el Derecho tiene tales características ${ }^{45}$. En parte

39 En sus términos: "Quienes aceptan la autoridad de un sistema jurídico lo ven desde el punto de vista interno, y expresan su apreciación de las exigencias de aquél en enunciados internos [...] Sin embargo, eso no los compromete a un juicio moral en el sentido de que es moralmente correcto hacer lo que el Derecho prescribe" [Hart, H. (2009). El concepto de Derecho (trad. Genaro Carrió). $3^{\text {a }}$ edición. Buenos Aires. Abeledo-Perrot, 251].

40 En concreto: "Si hay un punto de vista en que la obligación jurídica sea tratada, al menos presuntivamente, como obligación moral [...], un punto de vista en que el establecimiento y mantención de un orden jurídico, en cuanto distinto de uno discrecional o estáticamente consuetudinario, se considera un ideal moral, si no una apremiante exigencia de justicia, entonces tal punto de vista constituirá el caso central del punto de vista jurídico [...] el punto de vista de quienes no solamente apelan a la razonabilidad práctica, sino que también son razonables prácticamente, es decir: consecuentes". (Finnis, J. Ley natural y derechos... Ob. cit., 48). Contra el punto de vista interno de Hart, ver también: Finnis, J. “On Hart's Ways: Law as Reason and as Fact”. En Philosophy of Law. Collected Essays (vol. IV). Oxford. Oxford University Press, 230 y ss.

41 Alexy se defiende de la primera acusación llamando la atención respecto de que la "súper-inclusividad" no podría predicarse desde el punto de vista del observador y que, por lo tanto, tampoco es propia del positivismo jurídico. De la segunda se defiende aduciendo que existiría una diferencia fundamental entre las consideraciones indirectas de un observador y las directas de un participante: por ejemplo, frente a un nuevo caso, solo un tribunal situado en la perspectiva del participante podría considerar si es correcto ceñirse al voto de la mayoría del precedente o, por el contrario, fallar ahora según los argumentos del voto de la minoría. Confrontar: Alexy, R. “The Ideal Dimension...”. Ob. cit., 328.

42 Finnis. "Law as Fact...". Ob. cit., 95.

43 Para la idea de norma jurídica como razón para la acción, confrontar: Raz, J. (2002). Practical Reason and Norms. New York. Oxford University Press, 15 y ss. Para Finnis, las razones para la acción serían aquellas "que dan fundamento a la acción inteligente, motivada en esencia por un bien humano básico (más precisamente por el beneficio inteligible prometido por la realización de un bien básico". [Finnis, J. (1995). "Derecho natural y razonamiento jurídico" (trad. C. I. Massini-Correas). Persona y Derecho, Nro. 33, 10].

44 Finnis, J. (2017). “Qué es la Filosofía del Derecho?” (trad. C. I. Massini-Correas). En Estudios de Teoría del Derecho Natural. Ciudad de México. UNAM, 12.

45 En este trabajo no me detendré en el examen del enfoque metodológico finnisiano. 
por ello, Finnis ${ }^{46}$ discute que los sistemas jurídicos, para ser tales, tengan que formular una pretensión de corrección como postula Alexy. Insistiendo en el uso de la analogía, piensa que un sistema jurídico que impone obligaciones jurídicas que no son obligaciones morales -en tanto que no tienen nada que ver ni con Derechos morales ni con "la justicia en sentido moral"podría ser catalogado como un sistema muy defectuoso, pero no tendría por qué considerarse que no se trata de un sistema jurídico, o que tal cosa sería "conceptualmente imposible" 47 .

\section{II.3.2. Sobre la pertinencia de la versión alexiana de la fórmula de Radbruch ${ }^{48}$}

Como tuvimos oportunidad de ver (II.2.2), para Alexy, el no-positivismo incluyente que suscribe sería la única forma de ponderar adecuadamente las dimensiones real e ideal del Derecho, y, por lo tanto, los principios de seguridad jurídica y de justicia que le serían correlativos. La fórmula sintética que lo expresaría mejor sería: “[...] la injusticia extrema no es Derecho"49,

Para ello puede consultarse: Isler Soto, C. (2018). "Presupuestos metodológicos de la teoría iusnaturalista de John Finnis". Ius et Praxis, Nro. 24, 105-120.

46 Finnis, J. "Law as Fact...”. Ob. cit., 91-92. Confrontar también: Finnis, J. "Postscript". Ob. cit., 432.

47 Alexy replica atacando en detalle los argumentos de Finnis. Confrontar: Alexy, R. “The Ideal Dimension...”. Ob. cit., 315 y ss. Algo podré decir al respecto luego (III.2.2).

48 La idea original completa de Radbruch es la siguiente: "El conflicto entre la justicia y la seguridad jurídica se resolvió con la primacía del Derecho Positivo sancionado, aun cuando por su contenido sea injusto e inadecuado para beneficiar al pueblo, hasta que la contradicción entre la seguridad jurídica y la justicia alcance una medida tan intolerable que el Derecho, en tanto "derecho injusto", deba ceder a la justicia. Es imposible trazar una línea nítida entre los casos de arbitrariedad legal y las leyes válidas a pesar del contenido incorrecto; no obstante, otro límite puede distinguirse con mayor claridad: donde no hay siquiera una aspiración de justicia, donde la igualdad, la cual integra el núcleo de la justicia, fue negada conscientemente en beneficio de la regulación del Derecho, allí la ley no es solo 'derecho injusto', sino que carece por completo de la naturaleza del Derecho". [Radbruch, G. (2019). "Arbitrariedad legal y derecho supralegal”. En S. L. Paulson. La filosofía del Derecho de Gustav Radbruch. Y tres ensayos de posguerra de Gustav Radbruch (trad. A. Nava Tovar). Madrid. Marcial Pons, 220].

49 Para Alexy, la tesis de Radbruch tendría dos partes, la "fórmula de la intolerancia" por la que las leyes pierden su validez jurídica por razones objetivas: si son injustas de manera intolerable; y la "fórmula de la negación", por la que las mismas la pierden por razones subjetivas: si se niega conscientemente la igualdad que implica la justicia. Finalmente, llega a la formulación sintética citada, tras una un poco más extensa: "Las normas promulgadas conforme al ordenamiento y socialmente eficaces pierden su carácter jurídico o su validez jurídica cuando son extremadamente injustas". [Alexy, R. (2006). "Una defensa de la fórmula de Radbruch” (trad. J. A. Seoane). En R. L. Vigo (ed.). La injusticia extrema no es derecho (de Radbruch a Alexy). Buenos Aires. La Ley, 228-229]. 
lo que significaría que los defectos morales del Derecho socavan su validez jurídica solo si se transgrede el umbral de injusticia, esto es, cuando se producen violaciones extremas a los Derechos Humanos ${ }^{50}$. En realidad, ni el no-positivismo súper-incluyente ni el excluyente ofrecerían, a su juicio, una ponderación adecuada de los principios en juego, sino que apostarían equívocamente por dar demasiado peso o a la seguridad jurídica o a la justicia, respectivamente.

En concreto, Alexy ${ }^{51}$ cree que la versión finnisiana del no-positivismo súper-incluyente que se formula a través de la distinción que se ofrece en NLNR, entre a) la obligación jurídica en sentido "jurídico" o "intrasistemático" y b) la obligación jurídica en sentido "moral”, sería correcta desde la perspectiva del observador, pero debería ser rechazada desde la perspectiva central del participante. En su opinión, no solo daría absoluta prioridad a la seguridad jurídica y a la dimensión real del Derecho sobre sus contrapartidas, sino que sería de menor complejidad y de menor rendimiento práctico que la fórmula de Radbruch. Para Alexy, por ejemplo, tras el colapso de un régimen que habría gobernado eficazmente con leyes extremadamente injustas, la fórmula finnisiana no permitiría considerarlas nulas desde su origen en orden a la protección de los Derechos Humanos de sus víctimas, como sí lo haría la fórmula alexiana. No obstante, Alexy cree que algunas afirmaciones de Finnis en sus obras más recientes -en concreto cita la entrada "Natural Law Theories", de la Stanford Encyclopedia of Philosophy52_ lo acercarían a dicha fórmula, y con ello, al no-positivismo incluyente. Pero será mejor que me ocupe de estos detalles desde la réplica de Finnis.

Para el profesor australiano, la fórmula alexiana de Radbruch fallaría por simplificar cuestiones que son, en realidad, más complejas. Para Finnis ${ }^{53}$, existen tres sentidos del término "obligación jurídica” que ayudarían a responder a la pregunta acerca de cómo afecta la injusticia a la obligación de obedecer la ley, en concreto: a) en sentido intrasistemático o jurídico,

50 Alexy, R. "Some Reflections...”. Ob. cit., 108. Con más de detalle: Alexy R. "The Ideal Dimension...”. Ob. cit., 330-331.

51 Alexy, R. "Some Reflections...”. Ob. cit., 107-110.

52 Se le citará aquí por la edición: Finnis, J. (2017). "Teoría de la ley natural” (trad. C. I. Massini-Correas). En Estudios de Teoría del Derecho Natural (63-10). Ciudad de México. UNAM; traducción hecha sobre la versión de la entrada de 2011, la misma que se cita en el debate. Hubo luego una revisión sustantiva de la entrada en 2015 y otra en 2020, la que puede consultarse aquí: https://plato.stanford.edu/entries/natural-law-theories/, y que he tenido a la vista para la redacción de este ensayo.

53 Finnis, J. Ley natural y derechos... Ob. cit., 382-389. Como vimos en el párrafo anterior, la distinción entre a) y b) fue objeto central de la crítica de Alexy. Más recientemente, en el mismo sentido: Finnis, J. (2020). “The Nature of Law”. En J. Tasioulas (ed.). The Cambridge Companion to the Philosophy of Law. Cambridge. Cambridge University Press, 53. 
en la que "la premisa práctica de que la obediencia a la ley es socialmente necesaria es un principio estructural aislado del resto del razonamiento práctico"; b) en sentido moral, la "que presuntivamente se sigue de la obligación jurídica en sentido jurídico o intrasistemático"; y c) como obligación moral no derivada del carácter jurídico de una regla, sino de una fuente "colateral", como lo podría ser el hecho de que su cumplimiento en alguna medida resultase necesario para evitar que "el Derecho" (como un todo) "sea despreciado".

En ese orden de ideas, para Finnis ${ }^{54}$, toda norma jurídica generaría una obligación en sentido jurídico o intrasistemático - una razón para la acción- que sería invariable ${ }^{55}$ a causa de que se presume como exigida de esa manera por el bien común, el que requiere de autoridad para su coordinación y, por ello, de una obediencia al Derecho como, de hecho, éste haya sido establecido formalmente por dicha autoridad ${ }^{56}$. Pero por otro lado, tal norma no necesariamente generaría una obligación jurídica en "sentido moral" de obedecerla, pues esta sería más bien variable, en tanto que dependería no solo de la autoridad y del contenido de la norma, sino también de otras razones colaterales para la acción ${ }^{57}$. En ese sentido, podría decirse que el Derecho Positivo es un "objeto cultural” y el razonamiento jurídico es "(por lo menos en gran parte) un razonamiento técnico, no moral" 58 . En ese orden de ideas, Finnis ${ }^{59}$ cree que puede suscribir desde su teoría la tesis "la ley injusta no es ley", dado que una ley injusta -Derecho injusto-, no obstante

54 Finnis, J. Ley natural y derechos... Ob. cit., 341-346. Para mayor profundidad: Pereira Sáez, C. (2008). La autoridad del Derecho. Un diálogo con John M. Finnis. Granada. Comares, 198-217.

55 Finnis señala: "No sirve para pensar con claridad, ni para ningún fin práctico bueno, oscurecer la positividad del Derecho (Law) negando la obligatoriedad jurídica en el sentido jurídico o intrasistemático de una regla recientemente declarada jurídicamente válida y obligatoria por la más alta institución del 'sistema jurídico"'. (Finnis, J. Ley natural y derechos... Ob. cit., 384).

56 Con apoyo en Tomás de Aquino: Finnis, J. (2019). Tomás de Aquino. Teoría moral, política y jurídica (trad. F. Morales). Santiago. Instituto de Estudios de la Sociedad, 345-346.

57 En ese sentido, para Finnis: “[...] para el fin de juzgar las propias obligaciones jurídicas en el sentido moral, uno está facultado para dejar de lado las leyes que son 'injustas' [...] Tales leyes carecen de autoridad moral que en otros casos les viene simplemente de su origen, 'pedigrí' o fuente formal”. (Finnis, J. Ley natural y derechos... Ob. cit., 387-388).

58 Finnis, J. "Derecho natural y razonamiento...". Ob. cit., 21-22.

59 Finnis, J. “Teoría de la ley...”. Ob. cit., 64. Finnis se entiende siguiendo aquí a Tomás de Aquino, quien a su juicio habría sido menos tolerante con la injusticia que la fórmula alexiana de Radbruch. Confrontar: Finnis, J. (2017c). "Aquinas and Natural Law Jurisprudence". En G. Duke y R. P. George (eds.). The Cambridge Companion of Natural Law. Cambridge. Cambridge University Press, 41. 
tener validez jurídica intrasistemática, podría no ser ley -Derecho- en el sentido de no generar validez jurídica en sentido moral.

Ahora conviene exponer la tesis finnisiana que a Alexy le parece que podría introducir al profesor australiano en el no-positivismo incluyente. Para Finnis, un juez estaría autorizado moralmente "por el derecho superior y perenne de la humanidad"60 a apartarse de la norma que -no obstante haber sido aceptada como establecida positivamente en una determinada jurisdicción- ha perdido su carácter directivo, siempre que se haga el esfuerzo racional de compatibilizar esta nueva norma con el resto del sistema jurídico.

Pero a juicio de Finnis ${ }^{61}$, solo el "contexto discursivo" determinaría, si a) debe entenderse a la autorización como "jurídica" y a la norma dejada de lado como "no-derecho", en el sentido de jurídicamente inválida; o si b) debe más bien entenderse que el Derecho establecido por fuentes social-fácticas y dejado de lado por el juez -no obstante ser jurídicamente válido- habría sido demasiado injusto para ser obedecido y aplicado. Pues bien, a Alexy ${ }^{62}$ le parece que estos contextos discursivos dependen de las perspectivas, por lo que, desde la perspectiva principal del participante, Finnis habría aceptado implícitamente la fórmula de Radbruch.

Finnis ${ }^{63}$, en cambio -como vimos (II.2.2.) - piensa que un enfoque más preciso como el suyo, le permitiría sostener los tres tipos de no-positivismo alexiano, dependiendo del concepto finnisiano de obligación o validez jurídica que se crea conveniente aplicar contextualmente. Pero cree que su posición principal -desde el punto de vista interno moralmente comprometido, o perspectiva del participante- estaría más cerca del no-positivismo excluyente. Piensa, en concreto, que la fórmula de Alexy-Radbruch fallaría por su rudeza al sostener que hay un punto claro en el que la gravedad de la injusticia de una norma conllevaría a su invalidez jurídica al modo de un "todo o nada".

Para Finnis ${ }^{64}$, una norma significativamente injusta en cualquiera de sus formas tendría validez jurídica intrasistemática, pero no validez jurídico-moral -no obligaría moralmente por sí misma-, y no solo tras el colapso del sistema jurídico donde habría sido eficaz - como el ejemplo alexiano citado en este mismo acápite sugiere-, sino también durante su vigencia. No obstante, podría subsistir alguna obligación moral gradual de obedecer dicha norma en determinadas ocasiones, una vez hayan sido consideradas

60 Finnis, J. “Teoría de la ley...”. Ob. cit., 88.

61 Finnis, J. "Teoría de la ley...”. Ob. cit., 89.

62 Alexy, R. "Some Reflections...". Ob. cit., 110.

63 Finnis, J. "Law as Fact...". Ob. cit., 103-108.

64 Finnis, J. “Ley natural y derechos...”. Ob. cit., 380-381. 
todas las razones para la acción aplicables al caso concreto, lo que valdría no solo para un ciudadano, sino también para los tribunales. Dicho muy brevemente, para Finnis, básicamente por las razones expuestas, la fórmula de Alexy-Radbruch podría resultar funcional en muchas ocasiones, pero no establecería una necesidad conceptual, por lo que el no-positivismo incluyente no sería tampoco una verdad sobre el Derecho, o sobre la Filosofía o Teoría del Derecho ${ }^{65}$.

\section{El ensayo de una propuesta}

En esta segunda parte propiamente valorativa, en primer lugar (III.1.), desarrollaré brevemente por qué creo que es posible un diálogo entre las posturas alexiana y finnisiana. En segundo lugar (III.2.), en base a los matices de la discusión reseñada sobre las consecuencias jurídicas prácticas de los defectos morales del Derecho, propondré más extensamente mi punto de vista sobre el asunto. En tercer lugar (III.3.), aunque muy brevemente, daré mi opinión sobre las consecuencias jurídicas teóricas de dichas deficiencias.

\section{III.1. La posibilidad del diálogo entre los dos enfoques}

Creo que a pesar de las coincidencias de diverso calado observadas en los planteamientos de Alexy y de Finnis sobre el tópico, no sería del todo conveniente plantear que estamos frente a una "disputa de familia" 66 como la que Habermas ${ }^{67}$ veía en su intercambio de opiniones con Rawls sobre el uso público de la razón. Tampoco sería apropiado sugerir que el alexiano y el finnisiano sean algo así como dos modos de trabajar "en la tradición del Derecho Natural"68. Lo creo, básicamente, porque en el caso del debate del que

65 Alexy replica que, si bien puede haber coincidencias en cuanto al resultado entre su modo de lidiar con las normas injustas, su fórmula es completamente distinta por razones sistemáticas y es preferible a la propuesta de Finnis. A su modo de ver, la fórmula seguiría siendo una base no susceptible de ser reemplazada por una máxima hermenéutica tan abierta como el modo "todas las cosas consideradas" de Finnis. En ese sentido, la versión alexiana de la fórmula de Radbruch conllevaría a que el no-positivismo incluyente fuese una verdad sobre la naturaleza y la esencia del Derecho, y, por lo tanto, también sobre la Filosofía del Derecho. Confrontar: Alexy, R. “The Ideal Dimension...”. Ob. cit., 335-336.

66 Nava Tovar, A. Ob. cit., 163-164.

67 Habermas, J. (1995). "Reconciliation through the Public use of Reason: Remarks on John Rawls's Political Liberalism”. The Journal of Philosophy, Nro. 92, 110.

68 Crowe, J. (2019). Natural Law and the Nature of Law. Cambridge. Cambridge University Press, 137 y ss. 
acabo de dar cuenta, si bien existe una coincidencia en la tesis sustancial de que los defectos morales del Derecho afectan cualitativamente al mismo (II.1.), dicha coincidencia se da desde dos modos diferentes de concebir la racionalidad práctica, los que podríamos llamar sintéticamente, con Alexy ${ }^{69}$, "kantiano" y "aristotélico", enfoques cuyos presupuestos -más allá de ser ambos cognitivistas- son, en realidad, muy distintos ${ }^{70}$. Esa es la razón por la que pienso que no es viable plantear una especie de equivalencia de las tesis cuya semejanza es patente, ni tampoco una reducción de los argumentos de un enfoque a los del otro.

A pesar de lo señalado, creo que también sería un error concluir que es imposible un diálogo entre ambos enfoques. No solo porque el debate fácticamente lo demuestra, sino porque, además, tanto las divergencias como las coincidencias evidenciadas en el cuadro trazado muy sintéticamente (II) atestiguan sus frutos ${ }^{71}$. Creo que sobre esa base me resulta posible proponer a grandes rasgos una respuesta a la cuestión de las consecuencias jurídicas prácticas y teóricas de los defectos morales del Derecho, que se valga de algunas tesis centrales de uno y algunas del otro, aunque asumiéndolas sobre la base de la tradición de una racionalidad práctica aristotélica, que es la que suscribo. Me ocuparé de esa empresa en los acápites que siguen.

\section{III.2. Propuesta sobre las consecuencias jurídicas prácticas de los defectos morales del Derecho}

Trataré de justificar las dos consecuencias prácticas que considero más importantes, aunque me detendré significativamente más en la primera. Seguiré para ello un orden expositivo paralelo -aunque inverso- al de la

69 Alexy, R. El concepto y la validez... Ob. cit., 132 y ss.

70 En muy resumidas cuentas, me parece que son dos los rasgos sustanciales que diferencian a la racionalidad kantiana respecto de la aristotélica: a) el de una moral objetiva mínima procedimentalmente construida sin referencia a la realidad estructural humana tributaria -en última instancia- de una metafísica "enfática" en términos alexianos; y b) el de una racionalidad práctica procesal e ideal, en tanto que desvinculada de la realidad a causa de no plantearse como informada por la prudencia como virtud intelectual y moral que hace capaz a la razón de operar correctamente con las cosas contingentes a partir de la experiencia. Desde luego, adherir a alguna de las racionalidades de base no significa ni suscribir ni limitarse a los aportes de Kant o a los de Aristóteles. Ofrezco más detalles en: Chávez-Fernández Postigo, J. (2019). "El enfoque argumentativo de Manuel Atienza y la teoría estándar: dos problemas y un ensayo de solución”. Problema. Anuario de Filosofía y Teoría del Derecho, Nro. 13, 147 y ss.

71 Una buena expresión de ese diálogo de tradiciones -sin confusión entre las mismasse puede observar en: Seoane, J. A. (2006). "La doctrina clásica de lex iniusta y la fórmula de Radbruch. Un ensayo de comparación”. En R. L. Vigo (ed.),. La injusticia extrema no es derecho (de Radbruch a Alexy). Buenos Aires. La Ley, 277-288. 
parte descriptiva (II), por lo que me remito a lo ya sintetizado para evitar aquí reiteraciones excesivas.

\section{III.2.1. La injusticia extrema no es Derecho}

Me parece que Alexy ${ }^{72}$ tiene razón cuando sostiene que la perspectiva central desde la que se enfoca el Derecho debe rechazar la separación finnisiana entre el sentido jurídico y el sentido moral de obligación jurídica. Como vimos, Finnis mantiene una suerte de "doble dimensión de la validez jurídica de las normas positivas"73. Respecto de la validez jurídica en sentido intrasistemático, Finnis ${ }^{74}$ sostiene algo bastante semejante a lo que Raz $^{75}$ desarrolla a partir de las ideas de Kelsen ${ }^{76}$ : que la validez de una norma jurídica dependería de su pertenencia a un sistema jurídico o de su aplicabilidad en él, ambas reguladas necesaria y suficientemente, a su vez, por otras normas jurídicas válidas del sistema. Por lo que desde esta bifurcación, puede defender -a su modo- el teorema clásico lex injusta non est lex $x^{77}$.

En todo caso, cabe hacerse la pregunta: ¿qué clase de validez-obligatoriedad jurídica sería la "intrasistemática", que no se identifica con encontrarse bajo la amenaza estatal del uso de la fuerza en caso de desobediencia $^{78}$, ni con el deber moral de obedecerla, ya sea por su autoridad, ya sea en

72 Alexy, R. "Some Reflections...”. Ob. cit., 98.

73 Massini-Correas, C. I. (2017). "Estudio preliminar a John Finnis: Teoría del Derecho Natural”. En Finnis, J. Estudios de Teoría del Derecho Natural (trad. C. I. Massini-Correas). Ciudad de México. UNAM, L.

74 Finnis, J. Ley natural y derechos... Ob. cit., 307. En otro lugar señala: “[...] any interesting sense of 'legally valid' include 'legally obligatory". (Finnis, J. "Law as Fact...". Ob. cit., 103).

75 Raz, J. (1985). La autoridad del Derecho. Ensayos sobre Derecho y moral (trad. R. Tamayo y Salmorán). $2^{a}$ edición. Ciudad de México. UNAM, 191-196.

76 Por lo que creo que el reproche de Vigo resulta pertinente. Confrontar: Vigo, R. L. (2013). "Consideraciones sobre la visión de John Finnis acerca de la tesis 'la ley injusta no es ley"'. En Etcheverry, J. (ed.). Ley, moral y razón. Estudios sobre el pensamiento de John M. Finnis a propósito de la segunda edición de ley natural y Derechos Naturales. Ciudad de México. UNAM, 129 .

77 Finnis, J. “Teoría de la ley...”. Ob. cit., 64. Aunque no es, desde luego, la única forma de interpretarlo para defenderlo. Para Crowe: "[...] one might instead read the first reference to 'law' as referring to law in the ordinary sense of the term, while the second use of the term refers to the best available theory of law". (Crowe, J. Ob. cit., 151).

78 Para Finnis, este sería el primer sentido de "obligación jurídica", junto a los otros tres que revisamos (II.3.2), pero reconoce que el primero no tiene relevancia al analizar la pregunta acerca de los efectos de la injusticia sobre la obligación jurídica. Confrontar: Finnis, J. Ley natural y derechos... Ob. cit., 383. 
razón del bien común a pesar de su puntual contenido injusto ${ }^{79}$ Me parece que aceptar la obligatoriedad jurídica intrasistemática, como la plantea Finnis, implicaría aceptar que en los sistemas jurídicos pueden coexistir dos normas obligatorias aunque contradictorias: a) una injusta pero promulgada autoritativamente e intrasistemáticamente obligatoria, y b) otra justa como conclusión necesaria de un principio de razonabilidad práctica y moralmente obligatoria ${ }^{80}$.

Si interpreto bien a Finnis, me parece que una síntesis bastante apretada de su principal argumento para sostener la existencia de una validez intrasistemática del Derecho es que, desde el punto de vista interno comprometido moralmente con el Derecho -que incluye el externo- también podría identificarse como válida a una norma más o menos en los términos de Raz, lo que, además, ofrecería cierta seguridad jurídica al sistema como exigencia de justicia. Por ello, a Finnis le parece que una teoría seria acerca del Derecho debería considerar a una norma con validez-obligatoriedad jurídica intrasistemática invariable, aunque con validez-obligatoriedad jurídico-moral solo presuntiva y variable, dependiendo de su justicia y de las consideraciones concretas acerca del bien común.

Este enfoque teórico tendría, además, una ventaja operativa sobre la fórmula alexiana, pues evitaría resolver al modo "todo o nada" la validez jurídica de una norma intrasistemáticamente válida, sobre la base de la indeterminación de lo que podría implicar una injusticia extrema. En todo caso, debo puntualizar que lo que ofrece el enfoque de Finnis ${ }^{81}$ no puede ser sino -como señalé- solo cierta seguridad jurídica, porque debemos recordar que para el profesor australiano, por un lado, no solo el ciudadano sino también el juez estarían autorizados para apartarse del cumplimiento de normas positivas demasiado injustas para ser obedecidas o aplicadas, y por otro lado, la consideración del carácter de jurídicamente válidas de

79 Me parece que en una línea semejante opina Vigo. Ob. cit., 132.

80 Para una crítica semejante, confrontar: Nye, H. (2020). "Finnis's divided view of Law: problems for adjudicative theory". Jurisprudence. An International Journal of Legal and Political Thought, Nro. 11, 503 y ss. Para Finnis: “[...] whatever the practical reasoning into which it slots, the law's schema for practically understanding the legal obligations that the law claims to articulate and impose is one and the same -practical but not in itself-, as such, moral, though (in the central case): always apt for a moral reading by the morally concerned subject, yet far from empty of guidance, as non-optional, for those uninterested in moral concerns". [Finnis, J. (2013). "Reflections and Responses". En J. Keown y R. P. George (eds.). Reason, Morality, and Law: The Philosophy of John Finnis. Oxford. Oxford University Press, 556]. Sin embargo, se puede persistir con una pregunta similar: más allá de la coercibilidad, ¿qué clase de obligación o deber jurídicos entiende que tiene quien no se reconoce moralmente obligado por nada?

81 Finnis, J. “Teoría de la ley...”. Ob. cit., 84-89. 
dichas normas dependería, en definitiva, del contexto discursivo que se asuma $^{82}$.

En ese sentido, me parece que, al menos en este punto, lo que distingue principalmente el enfoque de Finnis del de Alexy son dos cuestiones: por un lado, el elemento material mediante el cual se hace viable determinar lo más objetivamente posible esa demasiada o extrema injusticia, $\mathrm{y}$, por otro lado, la rotundidad "todo o nada" con la que presenta Alexy su versión de la fórmula de Radbruch. Pues bien, a mí me da la impresión de que la tesis "la injusticia extrema no es Derecho" puede defenderse -paradójicamente- solo si, por un lado, se incorpora a la propia teoría algo semejante a los presupuestos del razonamiento jurídico finnisiano, en concreto: los bienes humanos básicos y las exigencias de la razonabilidad práctica, y, por otro lado, se asume la fórmula alexiana con cierta flexibilidad prudencial en su aplicación, también en el sentido de la racionalidad aristotélica que Finnis abraza y de la que Alexy ${ }^{83}$ expresamente se aparta.

Este no es el lugar para desarrollar ni siquiera brevemente dichos aspectos, así que apenas los apuntaré. Para Alexy ${ }^{84}$, una norma jurídica positiva que sea incompatible con "el núcleo de los Derechos Humanos básicos" de "validez eterna" -pone el ejemplo del homicidio injustificado- no sería Derecho, al ser extremadamente injusta y de ilicitud patente "para todo ser racional"85. Pues bien, para Alexy ${ }^{86}$, la existencia de los Derechos Humanos en general dependería de su justificabilidad, para la que se requeriría de un argumento explicativo inserto en la filosofía trascendental kantiana susten-

82 En todo caso, me parece que De Rosa no considera suficientemente esta tesis para su crítica a Finnis. (Confrontar: De Rosa. Ob. cit., 287). Por otro lado, tiendo a pensar que los "contextos discursivos" a los que se refiere Finnis, no se identifican con las "perspectivas" alexianas, como sugiere el profesor de Kiel. (Ver: Alexy, R. "Some Reflections...". Ob. cit., 110). Me parece que Finnis alude con ellos más bien a dos modos prudenciales diferentes -aunque igualmente verdaderos- de abordar la validez jurídica intrasistemática de la norma gravemente injusta desde la perspectiva del participante o del punto de vista interno comprometido moralmente.

83 Alexy, R. El concepto y la validez... Ob. cit., 132 y ss.

84 Alexy, R. (2016). "Derecho, discurso y tiempo" (trad. P. Rodríguez y J. A. Seoane). En La institucionalización de la justicia. $3^{\text {a }}$ edición ampliada. Granada. Comares, 64-70.

85 Esto no es exactamente lo mismo que plantear que los Derechos Humanos sean "absolutos" en el sentido de que sean inmunes a limitaciones tras el proceso de ponderación. Para Alexy, ni siquiera la dignidad en cuanto principio, lo sería, solo en cuanto regla. [Ver: Alexy, R. (2014). "La dignidad humana y el juicio de proporcionalidad". Parlamento y Constitución. Anuario, Nro. 16, 13]. Por otro lado, los derechos, independientemente de su estructura relativa o absoluta, podrían tener una validez absoluta, pero en el sentido de tener validez en cualquier sistema jurídico. [Revisar: Alexy, R. (2017b). "The Absolute and the Relative Dimensions of Constitutional Rights". Oxford Journal of Legal Studies, Nro. 37, 31-33].

86 Alexy, R. (2016). "La existencia de los Derechos Humanos" (trad. A. Ballesteros y J. A. Seoane). En La institucionalización de la justicia. $3^{a}$ edición ampliada. Granada. Comares, 95-107. 
tado en las reglas del discurso práctico general que irían -lógica y conceptualmente- de la libertad y la igualdad hasta la dignidad, pasando por la autonomía moral y la persona. Pero como la necesidad de la corrección en el discurso no generaría su necesidad en la acción, se requeriría complementariamente de un argumento "existencial”, el que se insertaría más bien en una línea de racionalidad hobbesiana ${ }^{87}$ justificando el paso del discurso a la acción a través de lo que sería un empírico "interés fuerte en la corrección”. A su juicio, esta fundamentación de los Derechos Humanos no sería propiamente objetiva, pero sí "semiobjetiva" y, por ello, suficiente.

En cambio, para Finnis ${ }^{88}$, los Derechos Humanos pueden ser justificados a partir de su vinculación, por un lado, con los bienes o valores humanos básicos, objetivos y evidentes: primeros principios pre-morales referidos al bienestar y al florecimiento humano, como la vida o el conocimiento; y, por otro lado, con las exigencias de la razonabilidad práctica: requerimientos metodológicos que permitirían elaborar los principios propiamente morales o ley natural a partir de dichos bienes. Dado que una de dichas exigencias implicaría la irracionalidad intrínseca de cualquier elección directa contra un bien humano básico, estos pocos deberes morales negativos que no admiten excepciones implicarían la existencia de algunos pocos Derechos Humanos de carácter absoluto 89 .

Por otro lado, para Finnis ${ }^{90}$, aunque estos derechos no se deducirían lógicamente de premisas empíricas o teóricas, en última instancia, serían tales en tanto que su titular es una persona con dignidad, la que sería tributaria de la naturaleza propia de todos los seres humanos, entendida en tér-

87 Sobre las características de esta racionalidad, confrontar: Alexy, R. (2005). "Teoría del discurso y Derechos Humanos”. En Teoría del discurso y Derechos Humanos (trad. L. Villar Borda). Bogotá. Universidad Externado de Colombia, 72.

88 Finnis, J. Ley natural y derechos... Ob. cit., 91-163.

89 El más obvio de estos derechos absolutos sería el de no verse privado directamente de la vida como medio para un fin ulterior. (Ver: Finnis, J. Ley natural y derechos... Ob. cit., 252-253). Sobre los absolutos morales, en extenso, revisar: Finnis, J. (1992). Absolutos morales. Tradición, revisión y verdad (trad. J. García Norro). Barcelona. EIUNSA, 39-56. Por otro lado, no pasaría lo mismo si se trata de deberes afirmativos de promover el bienestar. [Ver: Finnis, J (2011). "Introduction". En Human Rights \& Common Good. Collected Essays (vol. III). Oxford. Oxford University Press, 7]. Para un estudio sobre las diversas conexiones entre los principios morales y los Derechos Morales absolutos en Finnis, revisar: Zambrano, P. (2013). "Principios fundamentales como determinación de los principios morales de justicia. Una aproximación desde la distinción entre la perspectiva moral y la perspectiva jurídica de especificación de la acción humana”. En J. Etcheverry (ed.). Ley, moral y razón. Estudios sobre el pensamiento de John M. Finnis a propósito de la segunda edición de ley natural y Derechos Naturales. Ciudad de México. UNAM, 97 y ss.

90 Finnis, J. “Tomás de Aquino...”. Ob. cit., 208-230. 
minos semejantes a los de Aristóteles y Tomás de Aquino ${ }^{91}$. Por ello ${ }^{92}$, si una norma positiva exige a alguien obrar contra dichos absolutos morales, lejos de estar vinculado por ella o por razones colaterales, en realidad tendría la obligación de desobedecerla, sin perjuicio de que, aun siendo demasiado injusta, su validez jurídica intrasistemática podría defenderse si el contexto discursivo lo hace apropiado ${ }^{93}$.

Así las cosas, me parece que un enfoque como el de Finnis, que se inserta en la tradición de la racionalidad práctica aristotélica, ofrece ventajas de objetividad sobre enfoques como el de Alexy, pues permiten justificar la demasiada o extrema injusticia a partir de la transgresión no de contenidos normativos justificados ideal y empíricamente ${ }^{94}$, sino antes bien a partir de fines propios del modo humano de vida, tal cual la experiencia social nos lo muestra a través de una razón que no reduce la realidad a sus aspectos empíricos ${ }^{95}$, ni la moralidad de las acciones humanas a la correspondencia con una idealidad construida discursivamente ${ }^{96}$.

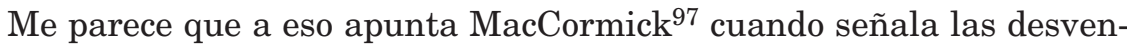
tajas de un modelo formal kantiano como el de Alexy, frente a uno sustancial aristotélico como el de Finnis ${ }^{98}$. En todo caso, lo que para Alexy podría considerarse una ventaja de su propio modelo - pues permitiría sostener una conclusión fuerte como "la injusticia extrema no es Derecho" a partir de una

91 Para Finnis: "[...] if we shift from the epistemological to the ontological mode, the same methodological principle, in its application to human beings, presupposes and thus entails that the goodness of all human goods [...] is derived from (i. e. depends upon) the nature which, bay their goodness, those goods perfect. For those goods -which as ends arte the rationes of practical norms or 'oughts'- would not perfect that nature were it other than it is". [Finnis, J. (2011). "Is and Ought in Aquinas". En Reason in Action. Collected Essays (vol. I). Oxford. Oxford University Press, 147].

92 Finnis, J. “Tomás de Aquino...”. Ob. cit., 349-350.

93 Finnis, J. “Teoría de la ley...”. Ob. cit., 89.

94 Para la defensa de una crítica semejante, confrontar: Alexy, R. "The Ideal Dimension...”. Ob. cit., 319-321.

95 A ello apunta Finnis cuando reclama una conexión con la realidad. Revisar: Finnis, J. "Law as Fact...". Ob. cit., 94.

96 Alexy reconoce la necesidad de un concepto metafísico para la fundamentación de los derechos, aunque se trataría de uno no "enfático", sino solo "constructivo". [Alexy, R. (2016). “Derechos Humanos sin metafísica?” (trad. J. A. Seoane y E. Sodero). En La institucionalización de la justicia. $3^{\mathrm{a}}$ edición ampliada, 75-89. Granada. Comares, 86 y ss.]. Si bien Finnis no deriva los bienes humanos básicos a partir de reflexiones teóricas sobre la metafísica, admite una filiación respecto de este concepto de tradición aristotélica que Alexy considera "enfático". (Finnis, J. “Tomás de Aquino...”. Ob. cit., 225-230).

97 MacCormick, N. (1982). "Legal Reasoning and Practical Reason”. Midwest Studies In Philosophy, Nro. 7, 280.

98 En una línea argumentativa semejante: MacCormick, N. (1983). “Contemporary Legal Philosophy: The Rediscovery of Practical Reason”. Journal of Law \& Society, Nro. 10, 10. 
justificación solo "semiobjetiva"-, en realidad, me parece una inconsistencia en el planteamiento: algo así como una teoría fuerte o robusta respecto de las consecuencias de la injusticia extrema sobre la validez jurídica, defendida como conclusión de unas premisas que se reconocen cognoscitivamente más débiles que la misma ${ }^{99}$.

En ese orden de ideas -aunque por razones diferentes a las de Alexy-, me parece un error sostener que una norma jurídica gravemente injusta -en el sentido de que atenta directamente contra Derechos Humanos absolutos en términos semejantes a los de Finnis- "obliga" o tiene "validez jurídica” en algún sentido razonable de los términos, una vez consideradas prudencialmente todas las razones para la acción y todas las circunstancias concretas relevantes para la solución de un problema jurídico ${ }^{100}$. Pienso que una norma de tal naturaleza pierde la obligatoriedad jurídico-moral presuntiva que proviene de su autoridad, por lo que mantiene de "Derecho" apenas su fenomenología empírica o apariencia - su formalidad o su eficacia-y, por ello, cierto reconocimiento autoritativo y social de que pertenece al sistema o que tiene aplicabilidad en él. Diría que se trata de una validez jurídica intrasistemática solo aparente, que podría llamarse "Derecho" en un sentido muy debilitado del término, pero solo a costa de llevar la analogía del lenguaje quizá demasiado lejos ${ }^{101}$.

99 Para Nava Tovar (ob. cit., 170-173), esta debilidad de las premisas éticas haría del planteamiento de Alexy uno más ponderado o equilibrado que el de Finnis, pues a diferencia de éste, el alexiano se caracterizaría por rechazar en el plano moral tanto un punto de vista escéptico, como uno absoluto. Sobre esta opinión, cabe hacer un par de observaciones. La primera, que el solo argumento de la ponderación no pareciera poder garantizar algo así como un justo medio o medida correcta entre principios en conflicto; en ese sentido, creo que se caería en una suerte de tautología que puede simplificarse más o menos así: “[...] cuando se contraponen principios, la solución correcta a los problemas jurídicos es una solución ponderada, y como a esta se llega a través del método de la ponderación en los términos alexianos, se concluye que el planteamiento de Alexy resulta más ponderado que el de Finnis". Incluso se podría decir que el propio Alexy parece proponer algo semejante. (Alexy, R. "Some Reflections...”. Ob. cit., 329 y ss.). La segunda cuestión que me permito objetar es que Nava Tovar no ofrece detalles de por qué atribuye a Finnis una rigidez ético-jurídica mayor que la de Alexy solo por el hecho de partir de premisas más fuertes, siendo que ambos comparten conclusiones bastante robustas sobre algunos Derechos Humanos, como he mostrado. En todo caso, me parece que una postura cognitivista moral fuerte -o al menos, más fuerte que la de Alexy- no implica necesariamente una falta de libertad para la realización de proyectos de vida plurales compatibles con los Derechos Humanos.

100 Por ello tampoco creo que una norma jurídica que por su autoridad obliga moralmente de manera presuntiva, lo haga “aislada parcialmente" del resto del flujo del razonamiento práctico. Para una defensa de este aspecto de la propuesta finnisiana, confrontar: Isler Soto, C. Ob cit., 120-121.

101 Creo que en ese sentido va la pertinente cuestión que esboza De Rosa. Ob. cit., 286. Para una defensa de la amplitud con la que Finnis se plantea la analogía del Derecho, confrontar: Seoane E. Ob. cit., 287-288. 
Por otro lado, se pueden interpretar algunas de las críticas de Finnis ${ }^{102}$ a la fórmula de Alexy-Radbruch en el sentido de que Alexy estaría buscando una salida más bien sistemática o racionalista -a todo o nada- para la norma extremadamente injusta, mientras que Finnis apelaría a una salida más bien prudencial que observe la complejidad y la contingencia de cada caso concreto, y que entienda la necesidad de justificar razonablemente si es que ante la grave injusticia pareciera no haber otro camino viable que impugnar la validez jurídica misma de la norma ${ }^{103}$.

En ese sentido, no deja de sorprender que Alexy ${ }^{104}$, por su parte, vincule la prudencia exclusivamente a la dimensión ideal del Derecho, lo que interpreto como una evidencia de que, en su enfoque, el puente entre la dimensión ideal y la real del Derecho queda sin poder plantearse en toda la complejidad que la contingencia de la realidad requiere. Por ello creo que la crítica finnisiana a la tesis "la injusticia extrema no es Derecho" debe quedar restringida a los presupuestos desde los que Alexy la asume, y no necesariamente a cómo la asumo aquí: desde una aplicación en consonancia con la razón práctica aristotélica, es decir, prudencialmente flexible para buscar la solución más justa posible en cada situación de injusticia extrema concreta $^{105}$.

\section{III.2.2. Observar el Derecho como si solo fuera un hecho}

Creo que una reflexión semejante a la del acápite anterior se puede hacer también respecto de la injusticia extrema de los sistemas jurídicos, aunque, desde luego, no es tan sencillo como en el caso de la norma jurídica considerada aisladamente. Por un lado, me parece -como a Finnis ${ }^{106}$ - que el problema de la validez de un sistema jurídico tomado en su conjunto no depende en sentido estricto de cuestiones conceptuales, ni resulta solidario

102 Finnis, J. "Law as Fact...”. Ob. cit., 107-108.

103 Sin perjuicio de ello, parece acertada la observación de Vigo en el sentido de que Finnis identificaría la razonabilidad práctica con la prudencia, cuando la tradición clásica concibe a esta última, antes bien, solo como el estatuto de máxima concreción de la razón práctica. (Vigo R. L. Ob. cit., 134-135). En mi opinión, una de las razones por las que Alexy ve la propuesta de Finnis de incorporar con matices la fórmula en discusión como hermenéuticamente demasiado abierta, es precisamente porque no alcanza a ver el peso directivo de los juicios de prudencia. Revisar: Alexy, R. “The Ideal Dimension...”. Ob. cit., 335.

104 Alexy, R. "The Ideal Dimension...”. Ob. cit., 332.

105 Me parece que algo semejante plantea Vigo R. L. Ob. cit., 136.

106 Finnis, J. “Law as Fact...”. Ob. cit., 91-92. Confrontar también: Finnis, J. "Postscript”. Ob. cit., 432. 
del problema de si formula o no una pretensión de corrección al menos implícita, en términos alexianos.

Por otro lado, soy de la opinión -como Alexy ${ }^{107}$ - de que se debe rechazar la tesis finnisiana respecto de que es posible la existencia de un "sistema jurídico"-aunque en un sentido muy debilitado del término- cuyos derechos y obligaciones jurídicas no tengan relación alguna ni con la justicia en sentido jurídico ni con los Derechos Morales. Creo, antes bien, que es posible defender analógicamente la juridicidad de un sistema normativo positivo con carencias importantes de justicia, pero que la analogía debería ceder si el mismo se edifica sobre cimientos institucionales conformados por un conjunto significativo de normas extremadamente injustas, en el sentido de que vulneran directamente Derechos Humanos absolutos, y con ellos, su presunción de validez-obligatoriedad moral de justicia ${ }^{108}$. También, en este caso, me parece que "la injusticia extrema no es Derecho", pero no como una fórmula a aplicarse al modo todo o nada frente a un supuesto de hecho claramente verificable, sino como una cuestión gradual que se debe discernir a través de juicios de prudencia tanto jurídicos como políticos, dependiendo de cada situación concreta, y una vez consideradas todas las cosas.

A mi juicio, la tesis propuesta en los párrafos anteriores puede sostenerse tanto desde el punto de vista interno finnisiano como desde la perspectiva del participante alexiana, lo que puede asumirse como la confirmación de que estamos frente a la mirada propiamente jurídica o central desde donde se conoce y se opera el Derecho, y que ambos enfoques son básicamente coincidentes en este punto. Pero cabe la pregunta, ¿cuánto del Derecho se puede conocer desde la mera observación? Como vimos (II.3.1.), para Finnis ${ }^{109}$, el mero observador capta el Derecho como un puro hecho social de poder, pero no como genuinas razones para la acción, y dado que la mirada del iuspositivista se circunscribe a la mera observación, éste no puede captar la generalidad del Derecho ni elaborar una teoría que sea capaz de dar cuenta de lo que el Derecho en realidad es y cómo opera. Para Alexy ${ }^{110}$, el mero observador puede captar toda la dimensión real del De-

107 Alexy, R. “The Ideal Dimension...”. Ob. cit., 314-317.

108 Creo que si afirmamos con Finnis que una norma jurídica formalmente válida y eficaz genera en razón de la autoridad de su fuente una presunción de validez jurídico-moral, se puede plantear lo propio respecto del sistema jurídico tomado en su conjunto como una unidad: que se presume -evidentemente de manera derrotable- que el sistema obliga como sistema jurídico-moral.

109 Finnis, J. “Law as Fact...”. Ob. cit., 87-95. Ver también: Finnis, J. Ley natural y derechos... Ob. cit., 37-51; Finnis, J. “¿Qué es la Filosofía...?”. Ob. cit., 12; y Finnis, J. (2003). "Law and What I Truly Should Decide". The American Journal of Jurisprudence, Nro. 48, 120.

110 Alexy, R. "Some Reflections...", Ob. cit., 103-109. Confrontar, también: Alexy, R. El concepto y la validez... Ob. cit., 37-41; y Alexy, R. "La justicia como corrección”. Ob. cit. 
recho, incluyendo -indirectamente- aquello que los ciudadanos toman por Derecho justo, pero no valorando -directamente- el Derecho justo en sí; por lo que sostiene que el iuspositivismo sería correcto desde esta perspectiva, salvo cuando pretende dar cuenta descriptivamente de un sistema jurídico que ni siquiera formula una pretensión de corrección.

Por mi parte, creo que Finnis tiene razón en cuanto a que el iuspositivismo -al circunscribirse a la perspectiva del observador o, en todo caso, a un punto de vista interno no comprometido moralmente- no puede captar el Derecho como realmente es, no solo porque los hechos por sí solos no ofrecen ningún elemento universal que haga posible la elaboración de una teoría digna de estimarse, sino también porque ese punto de vista no está abierto a los fines de las acciones de las personas ni a la finalidad del Derecho: la realización de la justicia, y sin esta dimensión interna se hace inviable el razonamiento jurídico. En ese sentido, me parece que Alexy tiene también algo de razón, pero solo si llevamos su tesis de la salvedad a la generalidad: cuando se observa el Derecho prescindiendo de su vínculo necesario con la justicia, se pueden describir ciertos hechos -sociológica, psicológica o históricamente-, pero no "jurídicamente", es decir, no en cuanto Derecho.

\section{III.3. Propuesta sobre las consecuencias jurídicas teóricas del debate}

Para terminar, señalaré muy brevemente las dos consecuencias teóricas que considero más importantes. Seguiré, para ello, un orden expositivo paralelo al de la parte descriptiva (II), por lo que me remito a lo resumido allí para evitar reiteraciones.

\section{III.3.1. Derecho Natural y Derecho Positivo}

Creo que tanto la doble dimensión o naturaleza dual alexiana, como la doble vida del Derecho finnisiana aciertan en proponer que cierto "monismo" -utilizado aquí como sinónimo de positivismo jurídico- debe rechazarse, aunque no es el objetivo de este trabajo elaborar argumentos contra alguna modalidad de dicha postura ${ }^{111}$.

111 Se puede consultar: Alexy, R. El concepto y la validez... Ob. cit., 13 y ss. y Finnis, J. (2017). "Sobre la incoherencia del positivismo jurídico" (trad. C. Pereira Sáez, supervisión C. I. Massini-Correas). En Estudios de Teoría del Derecho Natural. Ciudad de México. UNAM, 17 y ss. 
Sin embargo, si bien estoy convencido de que el aparato conceptual elaborado por Alexy puede ser de enorme utilidad para tender puentes al momento de discutir sobre la naturaleza del Derecho en general y de los Derechos Humanos o fundamentales en particular ${ }^{112}$, estoy básicamente de acuerdo con Finnis en que las categorías alexianas "real" e "ideal" no esclarecen suficientemente el problema. En particular, me parece que, a pesar de que la intención de Alexy ${ }^{113}$ sea que la "corrección de segundo orden" clausure de alguna manera esta dualidad a través de una consideración ponderada de ambas dimensiones en el único Derecho vigente, esta se lograría a través de dos tesis implícitas que se implican mutuamente: a) la realidad estaría constituida exclusivamente por sus aspectos empíricos, y b) los principios o Derechos Morales, aunque necesarios, serían elementos meramente ideales, críticos o racionales. Tampoco es que se pueda acusar a Alexy de incoherencia al construir un enfoque como este, considerando la matriz de racionalidad kantiana de la que parte expresamente; solo que creo que Finnis concibe más integradamente esta doble dimensión de la realidad jurídica, aunque no de manera enteramente satisfactoria en lo que a mí respecta, al menos desde el punto de vista que asume principalmente en el debate.

Como defendí en el acápite anterior (III.2.2.), creo que el Derecho entendido integralmente jamás deja de ser razón para la acción, y en ese sentido nunca es un mero hecho perfectamente observable y reconocible desde la mirada positivista, por lo menos sin desnaturalizarlo. Lo que diría es que las razones para la acción pueden estar intrínsecamente justificadas -en tanto que son o principios o conclusiones necesarias de la razón práctica- o pueden estar justificadas autoritativamente en base a razones para la acción intrínsecamente justificadas -en tanto determinaciones no necesarias de las primeras-, por lo que a las primeras podríamos llamarlas simplemente Derecho o ley natural y a las segundas: Derecho Positivo ${ }^{114}$. Desde luego no veo originalidad alguna en plantearlo de esa manera -el propio Finnis lo hace de manera muy semejante en otros lugares ${ }^{115}$-, pero tampoco veo la necesidad de abandonar dicha comprensión doble o dual del único Derecho válido y vigente, por alguna alternativa.

112 Confrontar: Chávez-Fernández Postigo, J. y Ríos Carrillo, P. (2019). "De la tesis de la doble naturaleza de Alexy a un 'iusnaturalismo moderado': una propuesta de comprensión de los derechos fundamentales implícitos a partir de la jurisprudencia constitucional de Perú y Chile". Revista Chilena de Derecho, Nro. 46, 177 y ss.

113 Alexy, R. "The Ideal Dimension...". Ob. cit., 323-324.

114 Revisar: Tomás de Aquino. Suma de Teología, I-II, q. 95 a. 2.

115 Aunque para Finnis la ley natural no es Derecho en sentido focal, sino solo en sentido analógico. Ver: Finnis, J. Ley natural y derechos... Ob. cit., 304-317. 


\section{III.3.2. No-positivismo y iusnaturalismo}

Desde mi punto de vista, Finnis ${ }^{116}$ acierta al sostener que la fórmula de Alexy-Radbruch no genera una necesidad conceptual y, además, que resulta un instrumento rudo si se le considera una especie de regla para resolver sistemáticamente -al modo todo o nada- los casos concretos de injusticia o de injusticia extrema. Sin embargo, creo que ello no implica que la fórmula deba ser rechazada ni como una verdad operativa -o correcta- sobre el Derecho, ni como una verdad teórica sobre él, siempre que se le entienda en términos semejantes a aquellos desde los que ha sido defendida aquí (III.2.1. y III.2.2.), y no se le interprete, además, como solidaria del no positivismo incluyente como defiende Alexy ${ }^{117}$. Dicho de otro modo: creo que el iusnaturalismo puede sostener la fórmula de Alexy-Radbruch, al menos como he intentado plantearla en los acápites previos.

Por otro lado, pienso que tiene sentido acuñar un término como no-positivismo jurídico o "postpositivismo"118 para aludir a algunas concepciones iusfilosóficas que rechazan las tesis básicas comunes que sostienen quienes se identifican con el positivismo jurídico -me refiero a la tesis de la fuentes sociales y a la de la separación necesaria entre Derecho y moral ${ }^{119}$, , pero que también rechazan las propias que defiende por lo general el iusnaturalismo, en el sentido de que a) no admiten la existencia de algo como el "Derecho Natural" en el sentido estricto del término, y b) no creen que el vínculo necesario entre el Derecho y la moral tenga que establecerse respecto de una moral racional y objetiva con vínculos al menos indirectos con una metafísica "enfática", en términos alexianos. Por ejemplo, un término como "no-positivismo constructivista" podría dar cierta cobertura a los nopositivismos no-iusnaturalistas, al menos a aquellos que sostienen que los principios morales que forman parte del Derecho deben ser establecidos por una razón crítica emparentada con el modelo kantiano ${ }^{120}$.

Quizá un argumento en contra de lo que acabo de proponer es que hasta el momento no he encontrado un filósofo del Derecho que comulgue con

116 Finnis, J. "Law as Fact...”. Ob. cit., 107.

117 Alexy, R. "The Ideal Dimension...". Ob. cit., 335.

118 Por ejemplo, se trata de la nomenclatura por la que se inclina: MacCormick, N. (2011). Instituciones del Derecho (trad. F. Atria y S. Tschorne). Madrid. Marcial Pons, 344.

119 Así las consideran, por ejemplo: Atienza, M. y Ruiz Manero, J. (2009). “Dejemos atrás el positivismo jurídico". En Para una teoría postpositivista del Derecho. Lima. Palestra, 145. Este asunto es muy controvertido, pero no corresponde aquí entrar a la polémica. Se puede consultar: Moreso, J. J. (2015). "El positivismo jurídico contemporáneo". En J. Fabra Zamora y Á. Núñez Vaquero (eds.). Enciclopedia de Filosofía y Teoría del Derecho (vol. I). Ciudad de México. UNAM, 171 ss.

120 Como el defendido por Alexy, R. El concepto y la validez... Ob. cit., 136 y ss. 
dichas ideas y esté satisfecho con la etiqueta que propongo. En ese sentido, creo que las fórmulas taxonómicas no sirven para reducir los matices de las posiciones iusfilosóficas a los rasgos que se consideran más o menos identitarios de las mismas, pero sí para poder rastrear mejor las tradiciones de pensamiento de las que los autores se sienten más o menos partícipes. En todo caso, este último me parece un argumento suficiente para aceptar la validez del rótulo "no-positivismo" o "postpositivismo", a pesar de los buenos argumentos en contra de Finnis ${ }^{121}$.

Finalmente, creo que tampoco resulta ser una buena idea agrupar a las concepciones no-positivistas o iusnaturalistas en uno $\mathrm{u}$ otro de estos rótulos, como de alguna manera lo hace Alexy respecto del primero de ellos, y lo acepta -quizá un poco a regañadientes- Finnis, a lo largo del debate ${ }^{122}$. Más allá de las coincidencias que han quedado suficientemente acreditadas, creo que varias de las diferencias de fondo no se deben exclusivamente a las peculiaridades intelectuales de los autores abordados, sino que conviene remitirlas a esas dos tradiciones distintas de racionalidad práctica -la kantiana y la aristotélica- que sellan, respectivamente, cada uno de los enfoques.

\section{Colofón}

Para terminar, quisiera aclarar que no me gustaría que lo último señalado en el párrafo anterior pueda interpretarse como una sutil invitación a evitar el contacto entre tradiciones, y no me refiero solo al contacto "externo", por decirlo de alguna manera. Me explico brevemente: debo confesar que durante la investigación y la redacción del trabajo fue una suerte de tentación constante explorar hasta qué punto Alexy y Finnis parecían acercarse por momentos -paradójicamente- a posiciones más propias de Tomás de Aquino y de Kant, respectivamente. Creo que hice bien en no ceder a ella, porque un esfuerzo de dicha naturaleza -independientemente de que hubiese podido llegar a buen puerto- me hubiera hecho imposible culminar este artículo oportunamente.

121 Finnis, J. “Tomás de Aquino...”. Ob. cit., 96-98.

122 Pero no solo ellos. Lo hace también, por ejemplo, La Torre, aunque en un sentido contrario al de Alexy, con el binomio "iusnaturalismo incluyente" y "iusnaturalismo excluyente", respectivamente. [La Torre, M. (2013). "Sobre dos versiones opuestas de iusnaturalismo: 'excluyente' versus 'incluyente"'. Revista Derecho del Estado, Nro. 30, 10 y ss.]. Me parece más interesante lo que ensaya Massini-Correas, quien utiliza el término "transpositivismo" para referirse en conjunto al binomio que he denominado aquí: "iusnaturalismo" y "no-positivismo constructivista". [Massini-Correas, C. I. (1997). "Los dilemas del constructivismo ético. Análisis a partir de las ideas de John Rawls". Persona y Derecho, Nro. 36, 167-171]. 
En todo caso, si este trabajo tiene alguna virtud, quizá sea haber intentado presentar ambas tradiciones de pensamiento a través de dos de sus representantes contemporáneos más importantes, quienes habían aceptado, además, entablar un diálogo sobre uno de los temas medulares de la Filosofía del Derecho contemporánea y de sus propios sistemas de pensamiento. Estudiarlo resultaba, para mí, una ocasión extraordinaria de que se manifieste la importancia de las estimulantes conexiones entre sus enfoques, evitando al mismo tiempo su confusión. En ese sentido, espero que el objetivo de este trabajo haya podido concretarse, al menos, en alguna medida.

\section{Referencias}

Alexy, R. (2004). El concepto y la validez del Derecho (trad. J. M. Seña, $2^{\text {a }}$ edición). Madrid. Gedisa.

Alexy, R. (2005). "La crítica de Bulygin al argumento de la corrección" (trad. P. Gaido). En Alexy, R. y Bulygin, E. La pretensión de corrección del Derecho. La polémica sobre la relación entre Derecho y moral. $5^{\mathrm{a}}$ reimp. Bogotá. Universidad Externado de Colombia, 53-84.

Alexy, R. (2005). "Teoría del discurso y Derechos Humanos". En Teoría del discurso y Derechos Humanos (trad. L. Villar Borda). Bogotá. Universidad Externado de Colombia, 61-91.

Alexy, R. (2006). "Una defensa de la fórmula de Radbruch" (trad. J. A. Seoane). En Vigo, R. L. (ed.). La injusticia extrema no es Derecho (de Radbruch a Alexy). Buenos Aires. La Ley, 227-251.

Alexy, R. (2011). "La doble naturaleza del Derecho" (trad. Jorge Portocarrero). En Bernal Pulido, C. (ed.). La doble dimensión del Derecho. Autoridad y razón en la obra de Robert Alexy. Lima. Palestra, 29-58.

Alexy, R. (2013). "Some Reflections on the Ideal Dimension of Law and on the Legal Philosophy of John Finnis". The American Journal of Jurisprudence, Nro. 58, 97110, https://doi.org/10.1093/ajj/aut009.

Alexy, R. (2013). “Una respuesta a Joseph Raz”. En Pavlakos, G. (ed.). Derecho, derechos y discurso. La Filosofía jurídica de Robert Alexy (trad. Jorge Portocarrero). Bogotá. Universidad Externado de Colombia, 61-85.

Alexy, R. (2014). "La dignidad humana y el juicio de proporcionalidad". Parlamento y Constitución. Anuario, Nro. 16, 9-27, https://parlamentoyconstitucion.cortesclm. es/recursos/articulos/PyC16_Alexy_Dignidad.pdf.

Alexy, R. (2016). "La justicia como corrección" (trad. J. A. Seoane y E. Sodero). En La institucionalización de la justicia. $3^{a}$ edición ampliada. Granada. Comares, 47-58.

Alexy, R. (2016). "Derecho, discurso y tiempo" (trad. P. Rodríguez y J. A. Seoane). En La institucionalización de la justicia. $3^{\mathrm{a}}$ edición ampliada. Granada. Comares, 59-74. 


\section{JOSÉ CHÁVEZ-FERNÁNDEZ POSTIGO}

Alexy, R. (2016). “Derechos Humanos sin metafísica?” (trad. J. A. Seoane y E. Sodero). En La institucionalización de la justicia. $3^{a}$ edición ampliada, Granada. Comares, 75-89.

Alexy, R. (2016). "La existencia de los Derechos Humanos" (trad. A. Ballesteros y J. A. Seoane). En La institucionalización de la justicia. $3^{\text {a }}$ edición ampliada. Granada. Comares, 91-107.

Alexy, R. (2017). “The Ideal Dimension of Law". En Duke, G. y George, R. P. (eds.). The Cambridge Companion to Natural Law Jurisprudence. Cambridge. Cambridge University Press, 314-341.

Alexy, R. (2017). "The Absolute and the Relative Dimensions of Constitutional Rights". Oxford Journal of Legal Studies, Nro. 37, 31-47. https://doi.org/10.1093/ ojls/gqw013.

Aquino T. (1989). Suma de Teología. Vol. II, trad. sección J. M. Rodríguez Arias. $2^{\text {a }}$ edición. Madrid. BAC.

Atienza, M. y Ruiz Manero, J. (2009). "Dejemos atrás el positivismo jurídico”. En Para una teoría postpositivista del Derecho. Lima. Palestra, 127-155.

Chávez-Fernández Postigo, J. (2019). "El enfoque argumentativo de Manuel Atienza y la teoría estándar: dos problemas y un ensayo de solución”. Problema. Anuario de Filosofía y Teoría del Derecho, Nro. 13, 129-160, http://dx.doi.org/10.22201/ iij.24487937e.2019.13.13718.

Chávez-Fernández Postigo, J. y Ríos Carrillo, P. (2019). "De la tesis de la doble naturaleza de Alexy a un 'iusnaturalismo moderado': una propuesta de comprensión de los derechos fundamentales implícitos a partir de la jurisprudencia constitucional de Perú y Chile". Revista Chilena de Derecho, Nro. 46, 177-201, https://doi. org/10.4067/S0718-34372019000100177.

Crowe, J. (2019). Natural Law and the Nature of Law. Cambridge. Cambridge University Press.

De Rosa, E. (2017). "Validez legal y corrección moral. El problema de la ley injusta en la teoría jurídica de John Finnis". Prudentia Iuris, Nro. 87, 277-298, https:// erevistas.uca.edu.ar/index.php/PRUDENTIA/article/view/981/944.

Finnis, J. (1992). Absolutos morales. Tradición, revisión y verdad (trad. J. García Norro). Barcelona. EIUNSA.

Finnis, J. (1995). "Derecho Natural y razonamiento jurídico" (trad. C. I. MassiniCorreas). Persona y Derecho, Nro. 33, 9-39, https://doi.org/10.15581/011.33.9-39.

Finnis, J. (2000). Ley natural y Derechos Naturales (trad. C. Orrego). Buenos Aires. Abeledo-Perrot.

Finnis, J. (2003). "Law and What I Truly Should Decide". The American Journal of Jurisprudence, Nro. 48, 107-129, https://doi.org/10.1093/ajj/48.1.107.

Finnis, J. (2011). "Postscript". En Natural Law and Natural Rights. $2^{a}$ edición. Oxford. Oxford University Press, 414-479.

Finnis, J. (2011). "Is and Ought in Aquinas". En Reason in Action. Collected Essays (vol. I). Oxford. Oxford University Press, 144-146.

Finnis, J. (2011). "Introduction". En Human Rights \& Common Good. Collected Essays (vol. III). Oxford. Oxford University Press, 1-16. 
Finnis, J. (2011). "On Hart's Ways: Law as Reason and as Fact”. En Philosophy of Law. Collected Essays (vol. IV). Oxford. Oxford University Press, 230-256.

Finnis, J. (2011). "Adjudication and Legal Change". En Philosophy of Law. Collected Essays (vol. IV). Oxford. Oxford University Press, 397-403.

Finnis, J. (2013). "Reflections and Responses". En Keown, J. y George, R. P. (eds.). Reason, Morality, and Law: The Philosophy of John Finnis. Oxford. Oxford University Press, 459-584.

Finnis, J. (2014). "Law as Fact and as Reason for Action: A Response to Robert Alexy on Law's 'Ideal Dimension'”. The American Journal of Jurisprudence, Nro. 59, 85-109, https://doi.org/10.1093/ajj/auu007.

Finnis, J. (2017). “Qué es la Filosofía del Derecho?” (trad. C. I. Massini-Correas). En Estudios de Teoría del Derecho Natural. Ciudad de México. UNAM, 1-16.

Finnis, J. (2017). "Sobre la incoherencia del positivismo jurídico" (trad. C. Pereira Sáez, supervisión C. I. Massini-Correas). En Estudios de Teoría del Derecho Natural. Ciudad de México. UNAM, 17-38.

Finnis, J. (2017). “Teoría de la ley natural” (trad. C. I. Massini-Correas). En Estudios de Teoría del Derecho Natural. Ciudad de México. UNAM, 63-100.

Finnis, J. (2017). "Aquinas and Natural Law Jurisprudence”. En Duke, G. y George, R. P. (eds.). The Cambridge Companion of Natural Law. Cambridge. Cambridge University Press, 17-56.

Finnis, J. (2019). Tomás de Aquino. Teoría moral, política y jurídica (trad. F. Morales). Santiago. Instituto de Estudios de la Sociedad.

Finnis, J. (2020). "The Nature of Law". En Tasioulas, J. (ed.). The Cambridge Companion to the Philosophy of Law. Cambridge. Cambridge University Press, 38-58.

Habermas, J. (1995). "Reconciliation through the Public use of Reason: Remarks on John Rawls's Political Liberalism". The Journal of Philosophy, Nro. 92, 109-131, https://doi.org/10.2307/2940842.

Hart, H. (2009). El concepto de Derecho (trad. Genaro Carrió). $3^{\text {a }}$ edición. Buenos Aires. Abeledo-Perrot.

Isler Soto, C. (2018). "Presupuestos metodológicos de la teoría iusnaturalista de John Finnis”. Ius et Praxis, Nro. 24, 101-128, http://www.revistaiepraxis.cl/index.php/ iepraxis/article/view/1078/539.

La Torre, M. (2013). "Sobre dos versiones opuestas de iusnaturalismo: 'excluyente' versus 'incluyente”. Revista Derecho del Estado, Nro. 30, 7-30, https://revistas. uexternado.edu.co/index.php/derest/article/view/3517.

MacCormick, N. (1982). "Legal Reasoning and Practical Reason”. Midwest Studies In Philosophy, Nro. 7, 271-286, https://doi.org/10.1111/j.1475-4975.1982.tb00095.x.

MacCormick, N. (1983). "Contemporary Legal Philosophy: The Rediscovery of Practical Reason". Journal of Law \& Society, Nro. 10, 1-18, https://doi. org/10.2307/1409998.

MacCormick, N. (2011). Instituciones del Derecho (trad. F. Atria y S. Tschorne). Madrid. Marcial Pons.

Massini-Correas, C. I. (1997). "Los dilemas del constructivismo ético. Análisis a partir de las ideas de John Rawls". Persona y Derecho, Nro. 36, 167-219, https://doi. org/10.15581/011.36.167-219. 


\section{JOSÉ CHÁVEZ-FERNÁNDEZ POSTIGO}

Massini-Correas, C. I. (2017). "Estudio preliminar a John Finnis: Teoría del Derecho Natural". En Finnis, J. Estudios de Teoría del Derecho Natural (trad. C. I. Massini-Correas). Ciudad de México. UNAM, XXI-LXIII.

Moreso, J. J. (2015). “El positivismo jurídico contemporáneo”. En Fabra Zamora, J. y Núñez Vaquero, Á. (eds.). Enciclopedia de Filosofía y Teoría del Derecho (vol. I). Ciudad de México. UNAM, 171-205.

Nava Tovar, A. (2017). "Non-Positivism, the Radbruch Formula, and the Dual Nature of Law. Some Remarks on the Finnis-Alexy Debate". En Borowski, M.; Paulson, S. L. y Sieckmann, J. R. (eds.). Rechtsphilosophie und Grundrechtstheorie. Robert Alexys System. Tübingen. Mohr Siebeck, 161-174.

Nye, H. (2020). "Finnis's divided view of Law: problems for adjudicative theory", Jurisprudence. An International Journal of Legal and Political Thought, Nro. 11, 503-529, https://doi.org/10.1080/20403313.2020.1772006.

Pereira Sáez, C. (2008). La autoridad del Derecho. Un diálogo con John M. Finnis. Granada. Comares.

Radbruch, G. (2019). "Arbitrariedad legal y Derecho supralegal". En Paulson, S. L. La Filosofía del Derecho de Gustav Radbruch. Y tres ensayos de posguerra de Gustav Radbruch (trad. A. Nava Tovar). Madrid. Marcial Pons, 213-225.

Raz, J. (1985). La autoridad del Derecho. Ensayos sobre Derecho y moral (trad. R. Tamayo y Salmorán). $2^{a}$ edición. Ciudad de México. UNAM.

Raz, J. (2002). Practical Reason and Norms. New York. Oxford University Press.

Seoane, J. A. (2006). "La doctrina clásica de lex iniusta y la fórmula de Radbruch. Un ensayo de comparación". En Vigo, R. L. (ed.). La injusticia extrema no es derecho (de Radbruch a Alexy). Buenos Aires. La Ley, 253-288.

Sodero, E. (2017). "Concepto de Derecho, moral y dignidad". En Alexy, R. et al. (ed.). Argumentación, Derechos Humanos y justicia. Buenos Aires. Astrea, 105-196.

Vigo, R. L. (2013). "Consideraciones sobre la visión de John Finnis acerca de la tesis 'la ley injusta no es ley". En Etcheverry, J. (ed.). Ley, moral y razón. Estudios sobre el pensamiento de John M. Finnis a propósito de la segunda edición de ley natural y Derechos Naturales. Ciudad de México. UNAM, 119-140.

Zambrano, P. (2013). "Principios fundamentales como determinación de los principios morales de justicia. Una aproximación desde la distinción entre la perspectiva moral y la perspectiva jurídica de especificación de la acción humana”. En Etcheverry, J. (ed.). Ley, moral y razón. Estudios sobre el pensamiento de John M. Finnis a propósito de la segunda edición de ley natural y Derechos Naturales. Ciudad de México. UNAM, 87-118. 